Bangladesh J. Zool. 49 (2): 301-319, 2021

ISSN: 0304-9027

eISSN: $2408-8455$

\title{
SEASONAL OCCURRENCE OF GASTROINTESTINAL PARASITES IN HORSE (EQUUS FERUS CABALLUS) FROM DHAKA CITY BANGLADESH
}

\author{
Hamida Khanum, Sharmin Musa*, Rimi Farhana Zaman \\ Fahmida Sarkar and Rawshan Ara Mitu \\ Parasitology Branch, Department of Zoology, University of Dhaka \\ Dhaka-1000, Bangladesh
}

\begin{abstract}
The study was conducted to understand the occurrence of gastrointestinal parasites in horse during June, 2017 to April, 2018 from Bangladesh National Zoo, Puran Dhaka and Rajarbagh Police Line of Dhaka city. A total of 48 faecal samples were collected from horses and examined by Direct Smearing technique and Formol Ether Concentration technique. Out of 48 samples 47 found positive for gastrointestinal parasitic infection with an overall prevalence of $97.92 \%$. Highest prevalence was identified $(77.1 \%)$ in Parascaris equorum, followed by $70.8 \%$ in Hymenolepis nana, $62.5 \%$ in Isospora sp., $50 \%$ in Ancylostoma duodenale, $39.6 \%$ in Toxocara sp., 35.4\% in Entamoeba sp., $25 \%$ in Trichuris sp., $20.8 \%$ in Fasciola hepatica $16.67 \%$ in Capillaria sp., $8.3 \%$ in Taenia sp. and Opisthorchis sinensis, $4.2 \%$ in Moniezia benedeni and Thysaniezia sp. Highest intensity $(72.97 \pm 46.32)$ was found for Isospora $\mathrm{sp}$. The $\mathrm{p}$ value was $0.01, \mathrm{p}<0.05$ so the prevalence rate was statistically significant.A significant difference was founded in prevalence between male and female horse where females were highly infected and also seasonal variation showed significant differences. Highest prevalence was recorded in winter and Rainy season (100\%) followed by summer (95\%). The intensity of parasites was highest in rainy season (63.38 \pm 79.94$)$ followed by summer (55.47 \pm 29.73$)$ and winter (49.5 \pm 28.58$)$.
\end{abstract}

Key words: Occurrence, gastrointestinal parasites, horse, seasons.

\section{INTRODUCTION}

Bangladesh is an agro-based country where livestock plays an essential role in improving rural farmers' socio-economic position. (Alam et al. 2015). Livestock contributes 1.78 percent to overall GDP and 12.64 percent to agriculture (Bangladesh Economic Review 2014). Both in urban and rural resource poor communities, horses are the essential source of agricultural energy and transport specially in developing world (Biffa and Woldemeskel 2006, Swann 2006). Horses and humans interact in a wide range of sporting

\footnotetext{
*Author for corresponding: <sharminsumi@yahoo.com>

C2021 Zoological Society of Bangladesh DOI: https://doi.org/10.3329/bjz.v49i2.56266
} 
events and non-competitive recreational pursuits, as well as in professional settings like law enforcement, agriculture, entertainment, and therapy. Wildlife captivity provides an unnatural system that upsets the equilibrium between parasite and host, generates a stressful environment, and causes animals to become ill or even die from parasite burdens that they would have survived in natural conditions. (Van Wyk and Boomker 2011). Parasite spread can be facilitated due to conditions produced by intensive animal husbandary. Zoo animals are maintained in confined areas which causes environmental contamination which creates a major concern for zoo animals. (Zasityte and Grikienciene 2002; Pencheva 2013).

A mixture of both external and internal parasites can infest horsed and it can be serious in young and undernourished horses ans mares (Hardin 1997; Anazi and Alyousif 2011; Brucknell et al. 1995; Lind et al. 1999; Larsen et al. 2002; Francisco et al. 2009; Lyons et al. 2012). Nematodes, parasites strongyles (Strongylus spp.), ascarids (Parascaris equorum), pinworms (Oxyuris equi) and bots (Gasterophilus spp.) have the highest prevalence. The most commonly diagnosed infections in horses among nematodes are strongyle and Parascaris equorum (horse ascarid) infections are (Epe et al. 2004; Hinney et al. 2011; Rehbein et al. 2013).

Most harmful parasite Strongyloides infect horse of all ages and can cause weight loss, weakness, anemia, diarrhea and even death (Khan et al. 2015). Parascaris equorum is highly prolific parasite and produces millions of extremely resistant eggs daily (Mitrea 2011). Besides strongyle and ascarid infections $h$

Pinworm (Oxyris equi), lungworms (Dictyocaulus arnfieldi), Habronema and Draschiorse infects the horse GI tract frequently (Brucknell et al. 1995, Francisco et al. 2009, Anazi and Alyousif 2011). Unless control measures such as a regular preventive deworming program and good management techniques to restrict parasite spread are implemented on a regular basis, the problem would most likely worsen, resulting in serious injury and death. (Watson et al. 2007). The type of parasite, seasonal climate variations in the area, the housing and feed sources employed, management tactics, and the age of the horse are all important factors in effective intestinal worm control. (Watson et al. 2007). Large and tiny Strongyles, as well as threadworm (Strongyloides westeri), have the highest occurrence rate, according to prior research. However, in all prior studies, the prevalence of Parascaris equorum was recorded as the second highest, but the prevalence was significantly lower than the current rate Mezgebu et al. (2013) reported a 43.8 percent prevalence, Sultan et al. (2014) a 15.51 percent prevalence, Anazi and Alyousif (2011) a 28.8 percent prevalence, Khan et al. (2010) a 36 percent prevalence, Adeppa et al. (2016) a 10.71 percent 
prevalence, and Musa et al. (2016) a 1.59 percent prevalence of Parascaris equorum. The variation in prevalence rates could be attributable to the geographic and climatic conditions, as well as the management procedure. Parascaris equorum eggs can resist severe conditions such as drying or freezing and hatching of larvae occasionally occurs in such circumstances (Soulsby, 1962) Hot and dry environment can be harmful for these parasites though they can survive freezing weather. Larvae can survive to up to seven weeks at summer temperatures and up to 31 weeks at winter temperatures.

Habronema muscae, Habronema microstoma and Drachia megastome live in the horse stomach., Habronema species live under a thick mucus coat on the surface of the stomach while Drachia live in large nodules in the stomach wall. THouse fly is the vector of these parasites. Donkeys and mules are common hosts of lungworms (Dictyocaulus arnfieldi) though they are frequently found in horses.. Lungworms eggs from gastrointestinal tract are passed out through host feces (Bliss 1999).

Cestodes and trematodes are also observed in horses. most common cestode in horses worldwide is Anoplocephala (Soulsby 1982, Taylor et al. 2007, Anderrsen et al. 2012, Gatachew et al. 2012). Orbit mites that live on pastures transmit Tapeworms (Anoplocephala magna, Anoplocephala perfoliata and Paranoplocephala mammillana) to horses by being ingested with grass. Serious illness including diarrhea, emaciation, colic, anaemia, haemorrhage and even death (Anazi and Alyousif 2011) are caused by these parasites. Of all the domestic livestock in Bangladesh, Prevalence and type of internal parasites affecting horses have not been determined to a great extent in Bangladesh though the prevalence and type of internal parasites affecting horses are highest of all domestic livestock and being continually exposed throughout their lives.

\section{MATERIAL AND METHOD}

The present study was done to investigate seasonal prevalence of gastrointestinal parasites in horse. Examination of faecal samples were done in Parasitology Laboratory, Dept. of Zoology, University of Dhaka. The study was conducted during the period of June, 2017 to April, 2018. This study was divided into three seasons in spite of being six seasons in Bangladesh (Chowdhury et al. 1979). Some seasons are short and continue with the other seasons (Banglapedia). A total of 48 faecal samples were collected from horse of three regions in Dhaka city. Out of 48 samples 8 samples were collected from Bangladesh National Zoo, 20 samples from Old Dhaka and 20 samples from Rajarbagh Police Line. These places were chosen because these are the locations where horses are kept for different purposes. Old Dhaka for transportation 
purposes, Police line for professional purposes and zoo for recreational purposes. These three places also has different kind of environment. Old Dhaka where horses are kept has an unhygienic environment and horse are kept in nonscientific way, while in zoo and pilice line horses are kept in captive protective scientific way. During sample collection the selected horses have been properly examined to collect different information related to the parasites. Age, sex, season were recorded carefully at the time of sample collection. The age of the selected horses was in between 4-18 years old in this study. Age of the selected horses was categorized into following three groups-: 4 year- 8 year, 9 year- 13 year and 14 year- 18 year. Age of the horses was confirmed by the keepers.

The faecal sample was collected randomly from the fields in the morning. Most animals defeacate in early morning after eating the previous day. Morning collection of fresh sample is also convenient to perform formol ether concentration technique to identify parasite eggs. Horses are herbivorous and all our study population ate grass and plants irrespective of their location. The $\mathrm{c}$

The collected samples were preserved according to age, sex and season. The faecal samples were preserved in $10 \%$ formalin during collection and then kept in $4{ }^{\circ} \mathrm{C}$ in laboratory. For the detection of parasites egg and ova, Formol Ether Concentration technique was applied (Cheesebrough 1987). The eggs of different helminthes were identified by using compound (10X) microscope. The 40X objective was also used to confirm ova and larvae (non-motile) and cysts. Eggs, ova and larvae observed under the microscope were identified following the descriptions and pictures of Chatterjee (1975), Cheng (1997), Soulsby (1982), Scimidth and Roberts (1989). Terminology was used ccording to Margolis et al. (1982) and Bush et al. (1997).

\section{RESULTS AND DISCUSSIONS}

In this study higher prevalence (77.1\%) was recorded for Parascaris equorum followed by Hymenolepis Highest nana (70.8\%) and Isospora sp. (62.5\%). Lowest prevalence $(2.1 \%)$ was in Gastrodiscus aegyptiacus and Oxyuris equi. The prevalence of parasite was statistically significant $(\mathrm{p}=0.01, \mathrm{p}<0.05)$. Highest intensity was observed in Isospora sp. $(72.97 \pm 46.32)$ followed by $H$ nana (8.47 \pm 5.04$) F$ hepatica $(4.4 \pm 1.45)$ and $P$ equorum (2.92 \pm 1.31$)$ and lowest intensity was $(1 \pm 0.04)$ for $G$ aegyptiacus and $O$ equi [Table 1]. Out of 15 parasite species, 2 species were protozoa, 3 species were trematode, 4 species were cestode and 6 species were nematode. Prevalence of protozoa was (70.8\%), trematode (31.25\%), 
Table 1: Overall prevalence and intensity of each gastro-intestinal parasite species in horse from three areas of Dhaka city

\begin{tabular}{lccccc}
\hline \multicolumn{1}{c}{ Name of parasites } & $\begin{array}{c}\text { No. of host } \\
\text { examined }\end{array}$ & $\begin{array}{c}\text { No. of host Prevalence } \\
\text { infected }\end{array}$ & $\begin{array}{c}\text { Total } \\
\text { (\%) }\end{array}$ & $\begin{array}{c}\text { Intensity } \\
\text { CPG } \mathbf{E P G}\end{array}$ \\
\hline Isospora sp. & 48 & 30 & 62.5 & 2189 & $72.97 \pm 46.32$ \\
Entamoeba sp. & 48 & 17 & 35.4 & 34 & $2 \pm 0.89$ \\
Hymenolepis nana & 48 & 34 & 70.8 & 288 & $8.47 \pm 5.04$ \\
Taenia sp. & 48 & 4 & 8.33 & 4 & $1 \pm 0.15$ \\
Moniezia benedeni & 48 & 2 & 4.2 & 2 & $1 \pm 0.08$ \\
Thysaniezia sp. & 48 & 2 & 4.2 & 2 & $1 \pm 0.08$ \\
Fasciola hepatica & 48 & 10 & 20.8 & 44 & $4.4 \pm 1.45$ \\
Gastrodiscus aegyptiacus & 48 & 1 & 2.1 & 1 & $1 \pm 0.04$ \\
Opisthorchis sinensis & 48 & 4 & 8.33 & 6 & $1.5 \pm 0.23$ \\
Ancylostoma duodenale & 48 & 24 & 50 & 29 & $1.2 \pm 0.63$ \\
Parascaris equorum & 48 & 37 & 77.1 & 108 & $2.92 \pm 1.31$ \\
Trichuris sp. & 48 & 12 & 25 & 13 & $1.1 \pm 0.41$ \\
Capillaria sp. & 48 & 8 & 16.67 & 14 & $1.75 \pm 0.49$ \\
Toxocara vitulorum & 48 & 19 & 39.6 & 28 & $1.47 \pm 0.70$ \\
Oxyuris equi & 48 & 1 & 2.1 & 1 & $1 \pm 0.04$ \\
& Total= 48, p value $=0.01(\mathrm{p}<0.05)$ & & \\
\hline
\end{tabular}

Table 2: Prevalence and intensity of gastro-intestinal parasites in male horse

\begin{tabular}{lccccc}
\hline Name of parasites & $\begin{array}{c}\text { No. of host } \\
\text { examined }\end{array}$ & $\begin{array}{c}\text { No. of host } \\
\text { infected }\end{array}$ & $\begin{array}{c}\text { Prevalence } \\
\text { (\%) }\end{array}$ & $\begin{array}{c}\text { Total } \\
\text { CPG/EPG }\end{array}$ & $\begin{array}{c}\text { Intensity } \\
\mathbf{I S D}\end{array}$ \\
\hline Isospora sp. & 22 & 12 & 54.5 & 1258 & 104.83 \\
Entamoeba sp. & 22 & 7 & 31.8 & 10 & 1.43 \\
Hymenolepis nana & 22 & 14 & 63.6 & 39 & 2.79 \\
Taenia sp. & 22 & 1 & 4.5 & 1 & 1 \\
Moniezia benedeni & 22 & 0 & 0 & 0 & 0 \\
Thysaniezia sp. & 22 & 1 & 4.5 & 1 & 1 \\
Fasciola hepatica & 22 & 4 & 18.2 & 14 & 3.5 \\
Gastrodiscus aegyptiacus & 22 & 0 & 0 & 0 & 0 \\
Opisthorchis sinensis & 22 & 2 & 9.1 & 4 & 2 \\
Ancylostoma duodenale & 22 & 11 & 50 & 14 & 1.27 \\
Parascaris equorum & 22 & 13 & 59.1 & 33 & 2.54 \\
Trichuris sp. & 22 & 6 & 27.3 & 7 & 1.17 \\
Capillaria sp. & 22 & 3 & 13.6 & 8 & 2.67 \\
Toxocara vitulorum & 22 & 9 & 40.9 & 16 & 1.78 \\
Oxyuris equi & 22 & 1 & 4.5 & 1 & 1 \\
& Total= 22, p value $=0.001(\mathrm{p}<0.0$ & $i)$ & & \\
\hline
\end{tabular}

cestode $(79.2 \%)$ and nematode $(93.75 \%)$. Intensity of protozoa was $(65.4 \pm 46.41)$, trematode $(3.4 \pm 1.47)$, cestode $(7.8 \pm 4.99)$ and nematode (4.3 \pm 2.03$)$. Highest prevalence was observed in nematode $(93.75 \%)$ and highest intensity was observed in protozoa $(65.4 \pm 46.41)$. The prevalence of the parasite was statistically significant $(\mathrm{p}=0.02, \mathrm{p}<0.05)$ [Table 2$)$. Out of 48 samples, 22 samples were from male and 13 parasite species were found. Prevalence (63.6\%) was highest in case of $H$ nana followed by $(59.1 \%)$ in $P$ equorum. Intensity was highest in Isospora sp. (104.83). The prevalence of the parasite was statistically significant $(\mathrm{p}=0.001, \mathrm{p}<0.05)$. (Table 2$)$. 
Table 3: Prevalence and intensity of gastro-intestinal parasites in female horse

\begin{tabular}{|c|c|c|c|c|c|}
\hline Name of parasites & $\begin{array}{l}\text { No. of host } \\
\text { examined }\end{array}$ & $\begin{array}{l}\text { No. of host } \\
\text { infected }\end{array}$ & $\begin{array}{c}\text { Prevalence } \\
(\%)\end{array}$ & $\begin{array}{c}\text { Total } \\
\text { CPG/EPG }\end{array}$ & $\begin{array}{c}\text { Intensity } \\
\pm S D\end{array}$ \\
\hline Isospora sp. & 26 & 18 & 69.2 & 931 & 51.7 \\
\hline Entamoeba sp. & 26 & 10 & 38.5 & 24 & 2.4 \\
\hline Hymenolepis nana & 26 & 20 & 76.9 & 149 & 7.5 \\
\hline Taenia sp. & 26 & 3 & 11.5 & 3 & 1 \\
\hline Moniezia benedeni & 26 & 2 & 7.7 & 2 & 1 \\
\hline Thysaniezia sp. & 26 & 1 & 3.8 & $\overline{1}$ & 1 \\
\hline Fasciola hepatica & 26 & 6 & 23.1 & 30 & 5 \\
\hline Gastrodiscus aequptiacus & 26 & 1 & 3.8 & 1 & 1 \\
\hline Opisthorchis sinensis & 26 & 2 & 7.7 & 2 & 1 \\
\hline Ancylostoma duodenale & 26 & 13 & 50 & 15 & 1.15 \\
\hline Parascaris equorum & 26 & 24 & 92.3 & 75 & 3.1 \\
\hline Trichuris sp. & 26 & 6 & 23.1 & 6 & 1 \\
\hline Capillaria sp. & 26 & 5 & 15.4 & 6 & 1.2 \\
\hline Toxocara vitulorum & 26 & 10 & 38.5 & 12 & 1.2 \\
\hline Oxyuris equi & 26 & 0 & 0 & 0 & 0 \\
\hline \multicolumn{6}{|c|}{ Total $=26, p$ value $=0.002(\mathrm{p}<0.05)$} \\
\hline
\end{tabular}

Prevalence and intensity of intestinal parasites in relation to sex of horse: Out of 48 samples, 22 were from male and 26 were from female Prevalence of parasites in female $(100 \%)$ was higher than in male $(95.45 \%)$. While, intensity was higher in male $(71.71 \pm 68.72)$ than female (48.35 \pm 37.20$)$ (Fig. 2. Table 4).

The prevalence $(92.3 \%)$ was highest in case of $P$. equorum and second highest was for $H$ nana (76.9\%). Intensity was highest in Isospora sp. (51.7). The prevalence of the parasite was statistically significant $(p=0.002, p<0.05)$ (Table 3).

Prevalence and intensity of gastro-intestinal parasites in horse in relation to age: Prevalence of gastro-intestinal parasites was higher $(100 \%)$ in case of age group (4-8) years and (14-18) years then (96.43\%) in (9-13) years and intensity was highest (109.83 \pm 73.33$)$ in (14-18) years age group (Table 4$)$.

From 48 samples, 8 samples were under (4-8) years age group and 12 parasite species were found (Fig. 3, 4). Prevalence $(97.5 \%)$ was highest in case of $P$ equorum and second highest $(87.5 \%)$ was for $H$. nana. Intensity was highest in Isospora sp. $(45 \pm 22.50)$. The prevalence of the parasite was statistically significant $(\mathrm{p}=0.002, \mathrm{p}<0.05)$.

From 48 samples, 12 samples were under (14-18) years age group and 11 parasite species were found. Prevalence (66.7 \%) was highest in case of Isospora sp. followed by $58.3 \%$ and $41.67 \%$ in Ancylostoma sp. and T. vitulorum respectively. The lowest prevalence was $8.3 \%$ for Taenia sp., M. benedeni and Capillaria sp. Intensity (141.25 \pm 77.92$)$ was highest in Isospora sp. and lowest in Taenia sp. and $M$. benedeni $(1 \pm 0.15)$. The prevalence of the parasite was 


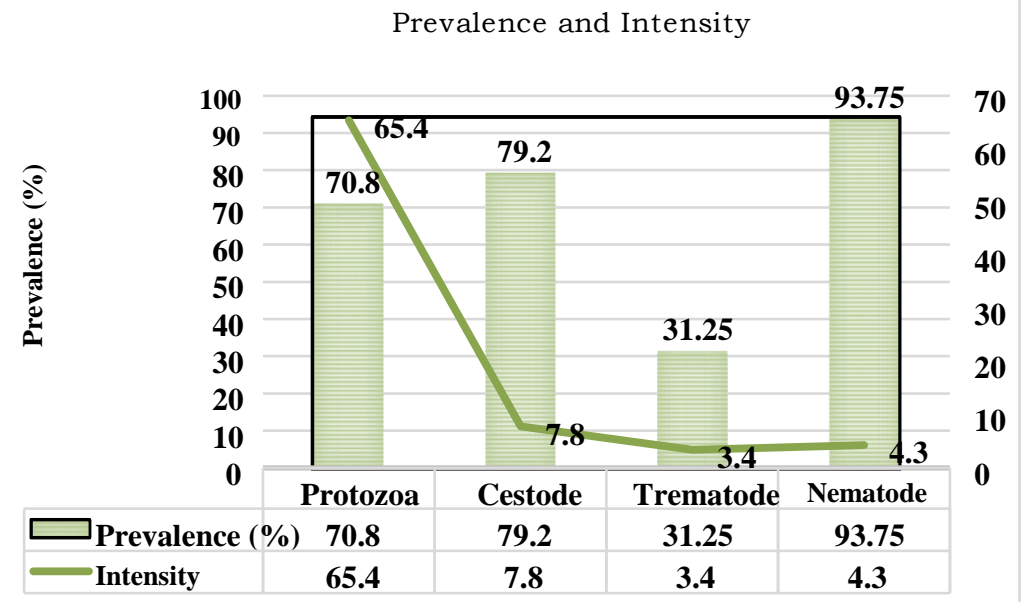

Fig. 1. Group wise prevalence and intensity of parasites among horse from three areas of Dhaka city Total $=48, p$ value $=0.02(p<0.05)$

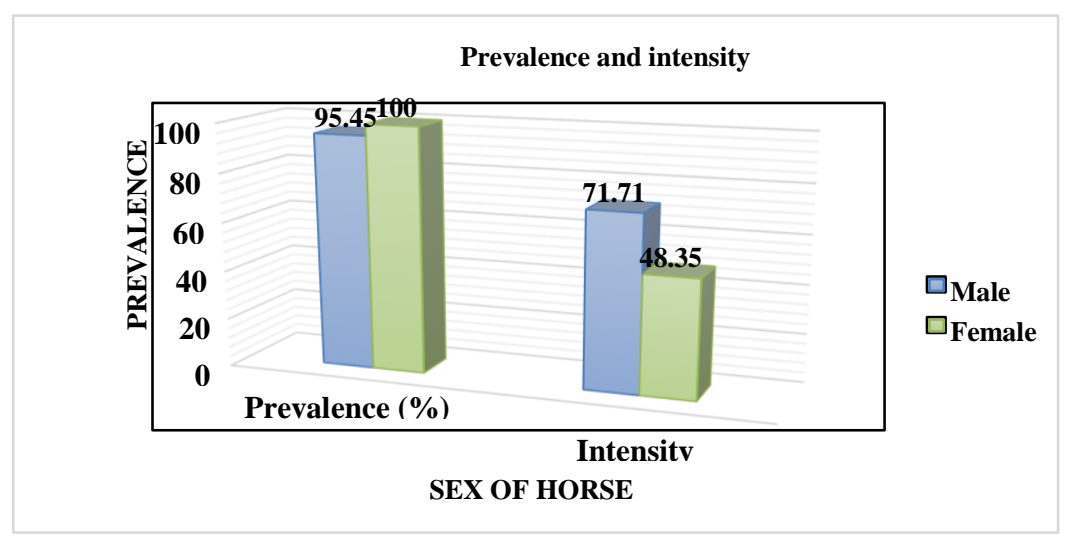

Fig. 2. Overall prevalence and Intensity of gastro-intestinal parasites in male and female horse

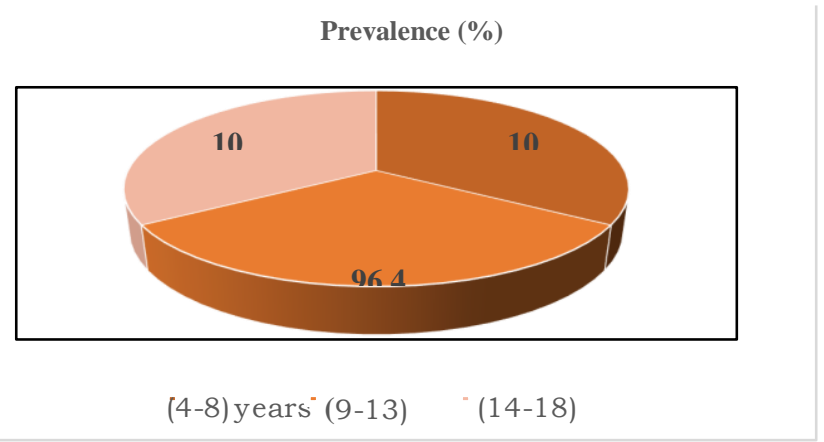


Fig. 3. Prevalence and intensity of gastro-intestinal parasites of horse in relation to age

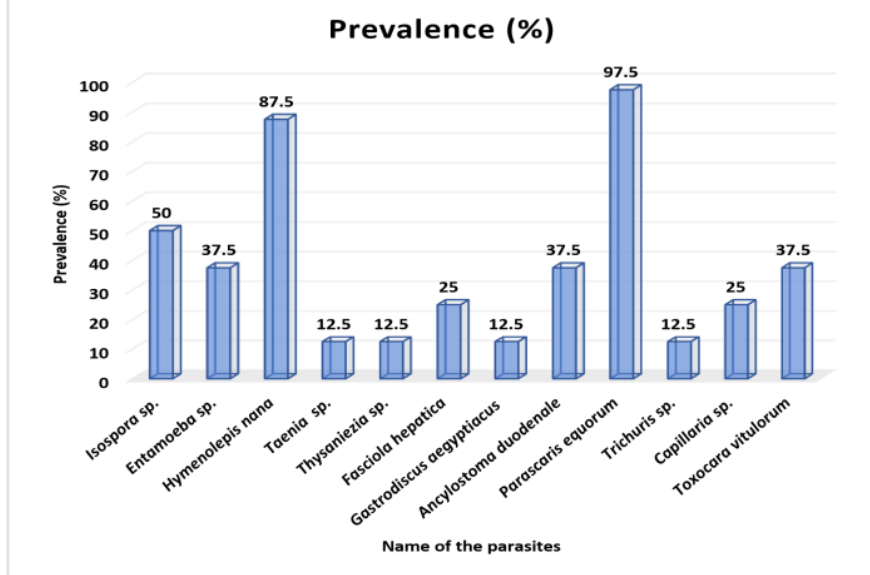

Fig. 4. Prevalence and intensity of gastro-intestinal parasites in (4-8) years host age group

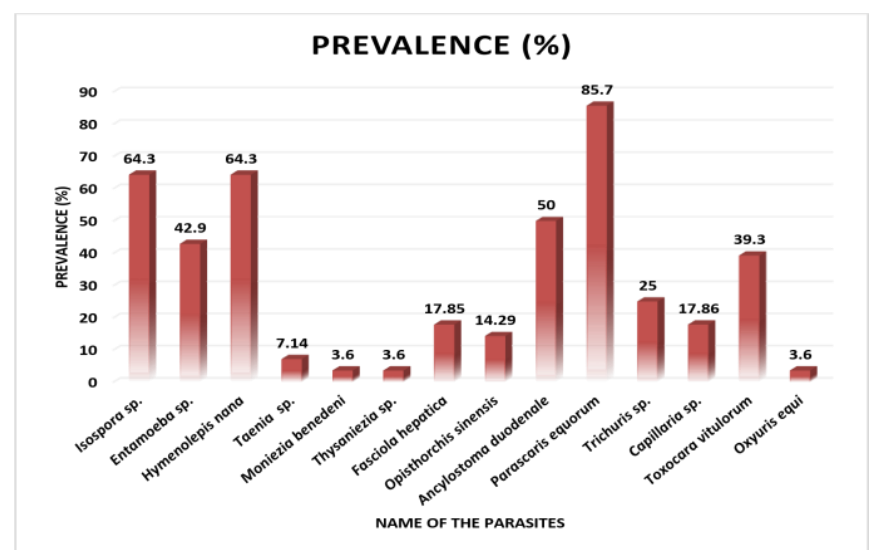

Fig. 5. Prevalence of gastro-intestinal parasites in (9-13) years host age group Total $=12, \mathrm{p}$ value $=$ $0.0007(\mathrm{p}<0.05)$

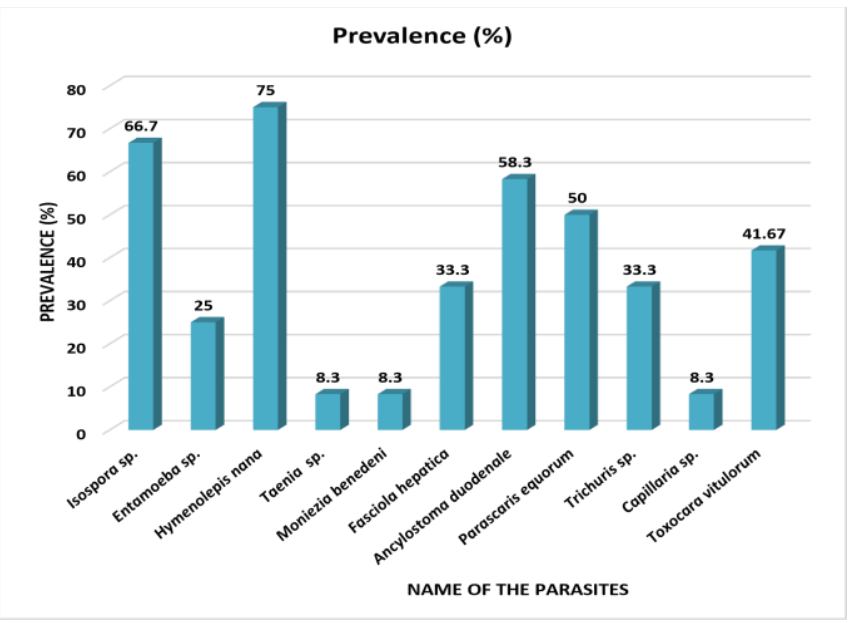


Fig. 6. Prevalence of gastro-intestinal parasites in (14-18) years host age group

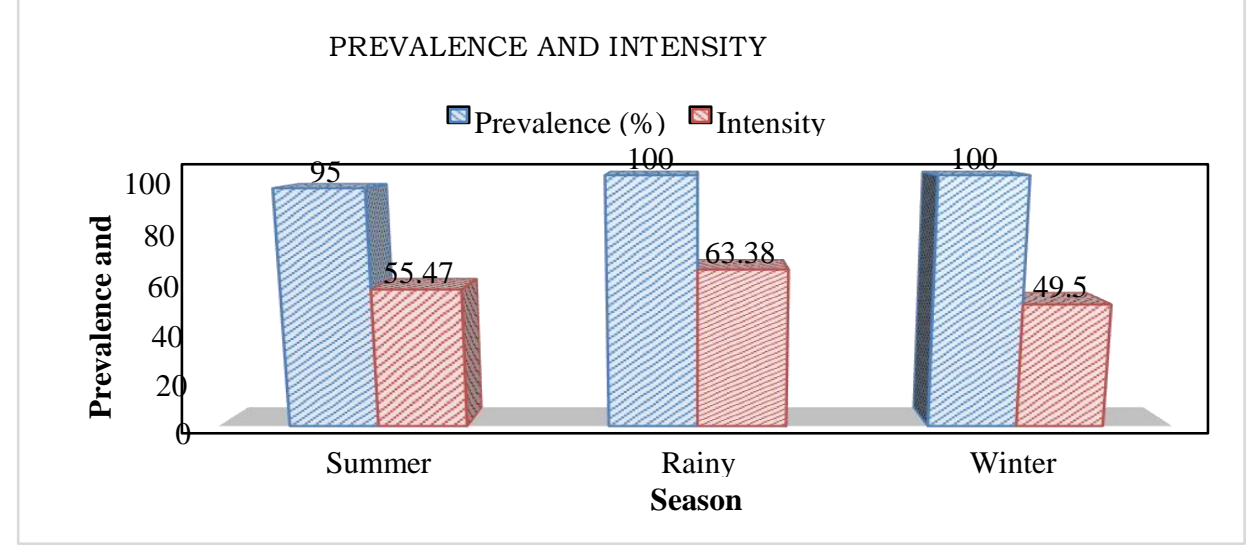

Fig. 7. Overall prevalence and intensity of gastro-intestinal parasites in horse in different seasons

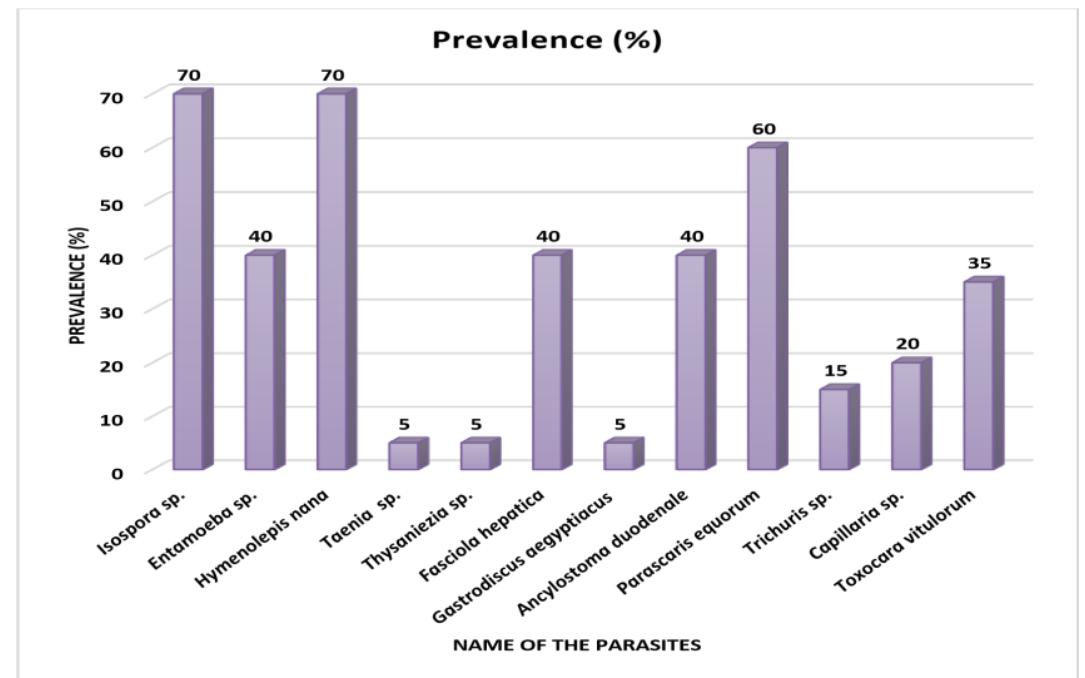

Fig.8. Prevalence and intensity of gastro-intestinal parasites of horse in summer season

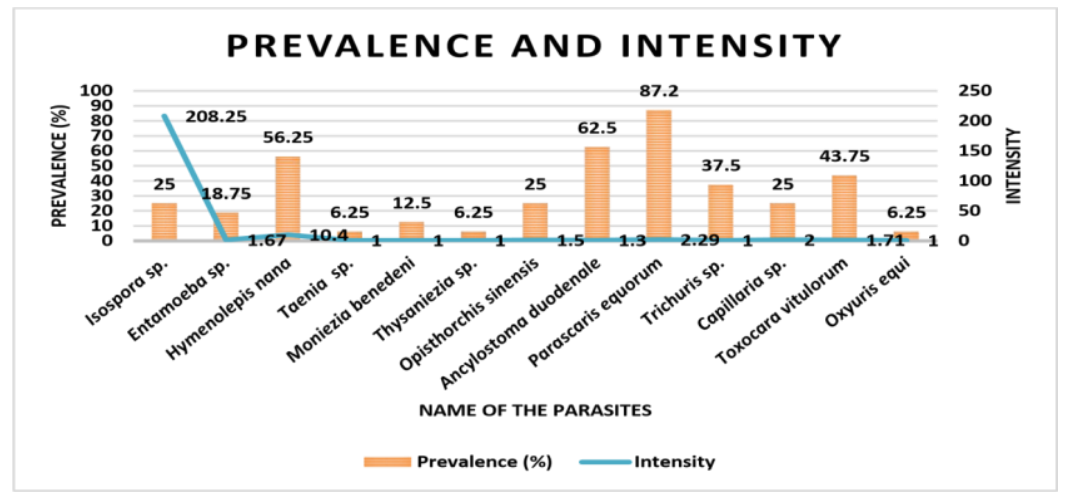

Fig. 9. Prevalence and intensity of gastro-intestinal parasites of horse in rainy season 


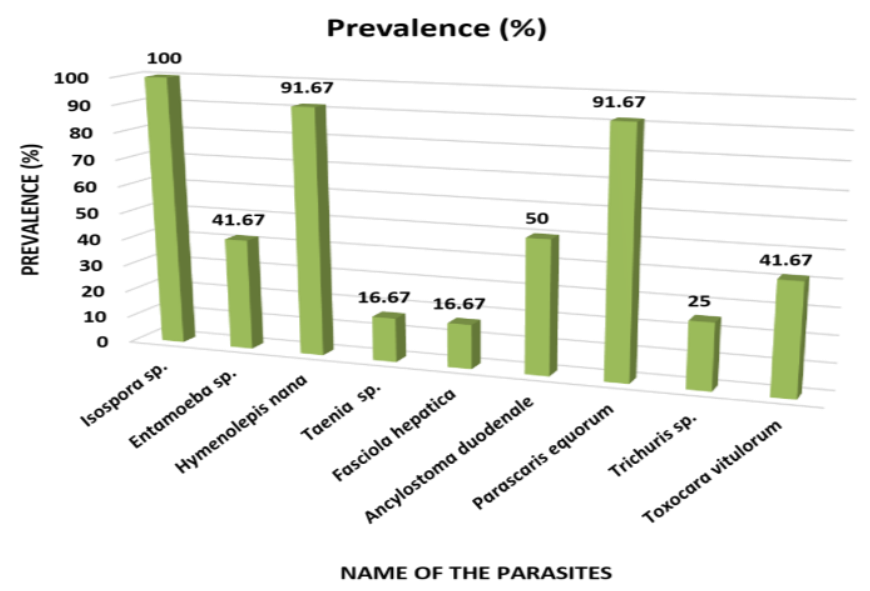

Fig.:10. Prevalence and intensity of gastro-intestinal parasites of horse in winter

statistically significant $(\mathrm{p}=0.0007, \mathrm{p}<0.05)$. (Fig. 6). Out of 48 samples examined, 28 samples were under (9-13) years age group and 14 parasite species were found (Fig. 5). Prevalence (85.7\%) was highest in case of $P$. equorum and second highest (64.3\%) was for $H$. nana and Isospora sp. The lowest prevalence was $3.6 \%$ for $O$. equi, $M$. benedeni and Thysaniezia sp Intensity was highest in Isospora sp. (45 \pm 22.50$)$ and lowest in $O$. equi, M. benedeni and Thysaniezia sp. $(1 \pm 0.07)$. The prevalence of the parasite was statistically significant ( $\mathrm{p}=0.001, \mathrm{p}<0.05)$ [Fig. 5].

Prevalence and intensity of intestinal parasites in horse in relation to season: From 48 samples, 20 were collected in summer season, 16 in rainy season and 12 were in winter season. The highest prevalence was $100 \%$ recorded in rainy and winter season and lowest found in summer that was 95\% (Fig. 8). In case of intensity, the highest was found in rainy season and lowest in winter where the rate of intensity was moderate in rainy season (Fig. 9).

It was observed that the prevalence was highest in Isospora sp. and Hymenolepis nana and that was $70 \%$ and second highest $(60 \%)$ was for Parascaris equorum. The lowest prevalence was $5 \%$ for Gastrodiscus aegyptiacus, Taenia sp. and Thysaniezia sp. Intensity was highest in Isospora sp. (57.29 \pm 34.60$)$ and lowest in Gastrodiscus aegyptiacus, Taenia sp. and Thysaniezia sp. $(1 \pm 0.10)$. The prevalence of the parasite was statistically significant $(\mathrm{p}=0.001, \mathrm{p}<0.05)$.

The prevalence was highest in Parascaris equorum and that was (87.2\%) and second highest (62.5\%) was for Ancylostoma duodenale. Lowest prevalence was 
$6.25 \%$ for Taenia sp., Thysaniezia sp. and Oxyuris equi. Intensity (208.25 \pm 78.09$)$ was highest in Isospora sp. and lowest $(1 \pm 0.12)$ in Taenia sp., Thysaniezia sp. and Oxyuris equi. The prevalence of the parasite was statistically significant $(\mathrm{p}=$ $0.001, \mathrm{p}<0.05)$.

In present observation, prevalence was highest in Isospora sp. and that was (100\%) and second highest was $91.67 \%$ for Parascaris equorum and

Eggs and cysts of gastrointestinal parasites were identified according to their taxonomy, morphology and characteristics. These are as follows.

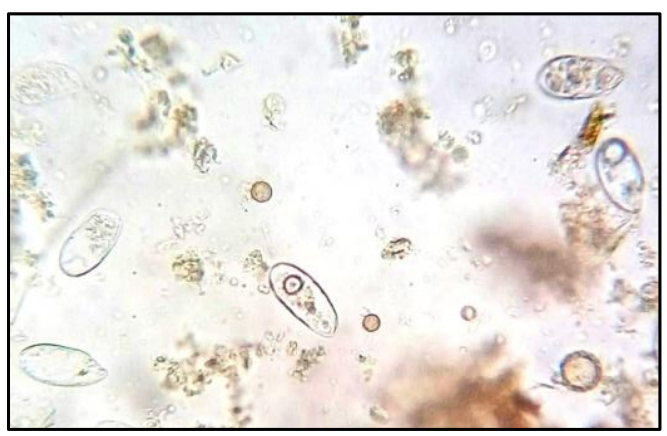

1. Cyst of Isospora

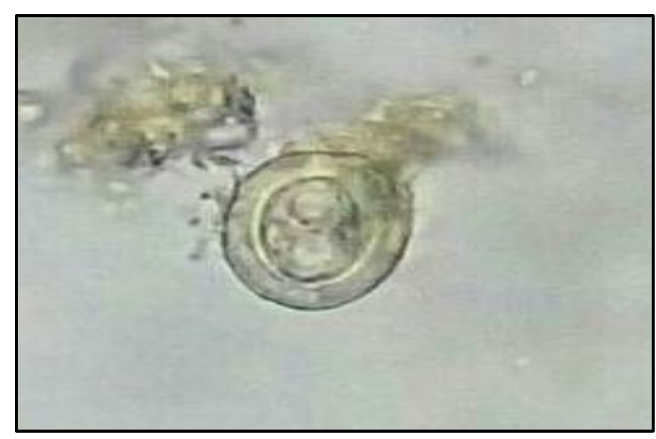

3. Egg of Hymenolepis nana

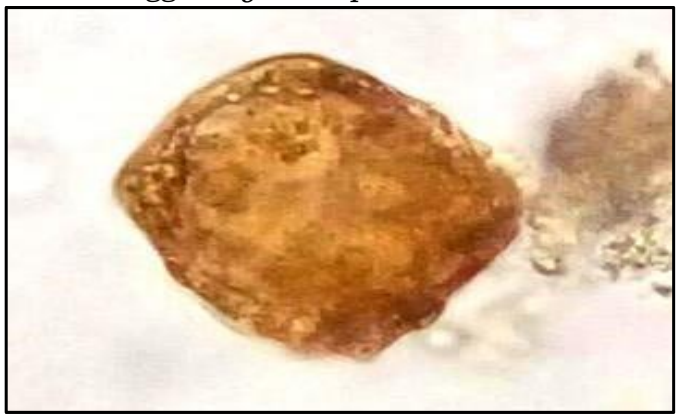

5. $\quad$ Egg of Moniezia benedeni

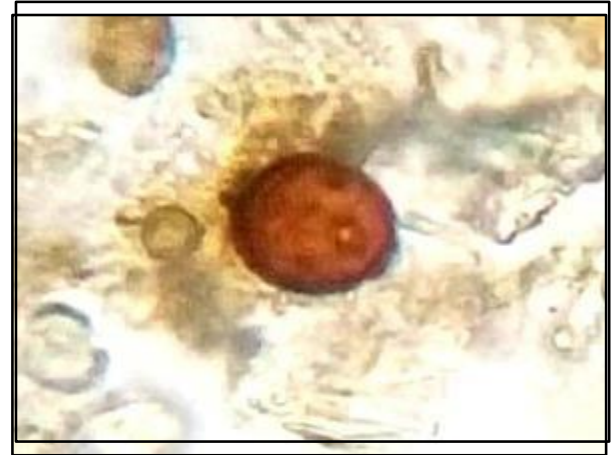

2. Cyst of Entamoeba

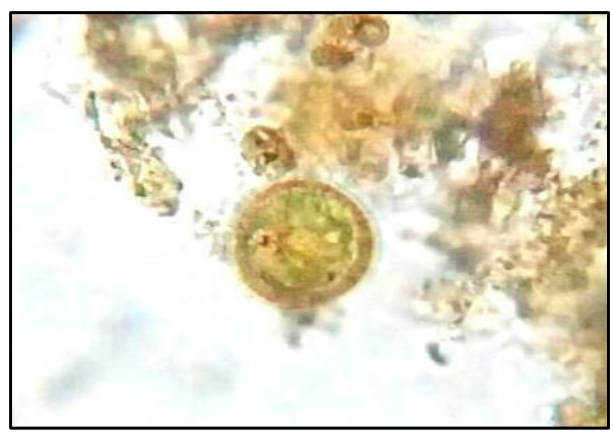

4. Egg of Taenia

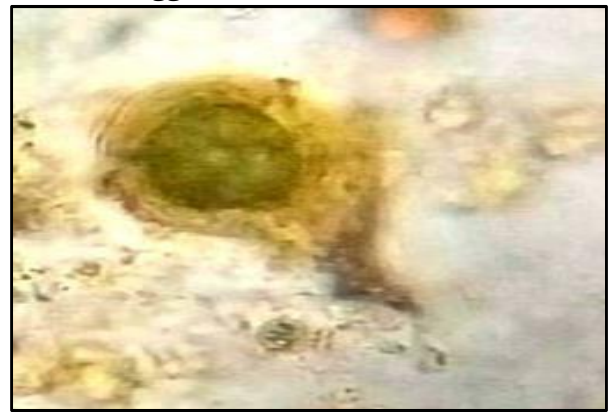

6. Egg of Thysaniezia sp. 

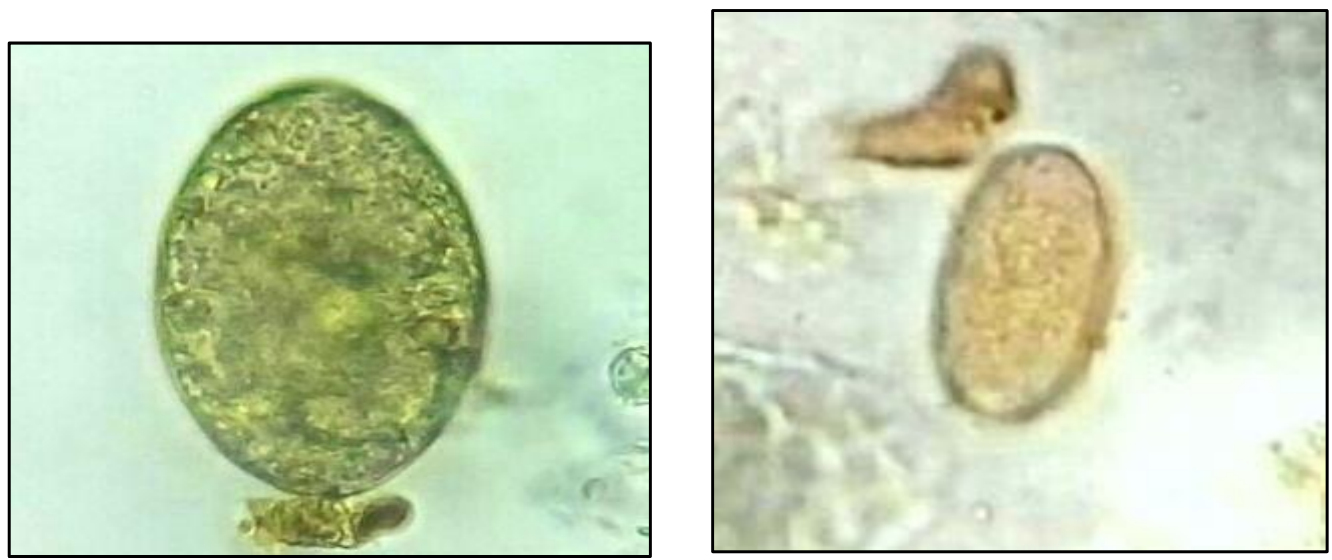

7. Egg of Fasiola hepatica

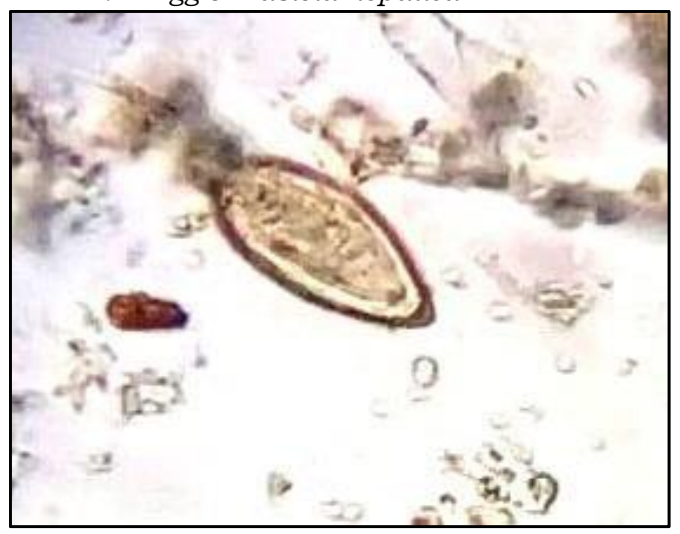

8. Egg of Gastrodiscus aegyptiacus

10.Egg of Opisthorchis sinensis

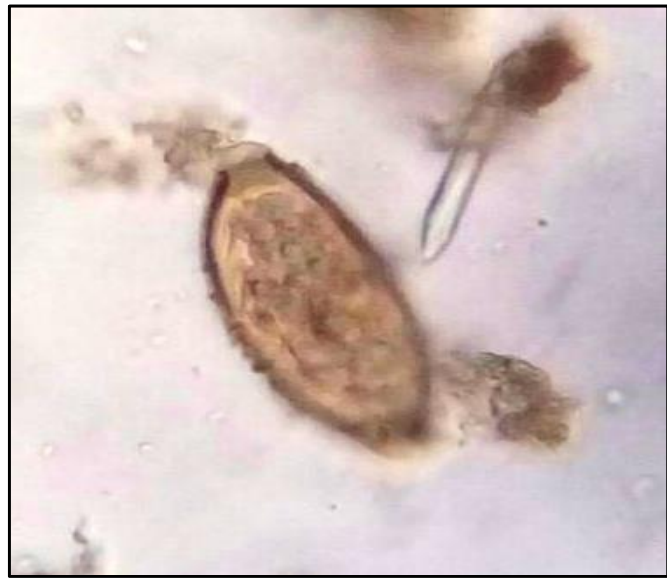

11. Egg of Trichuris trichura

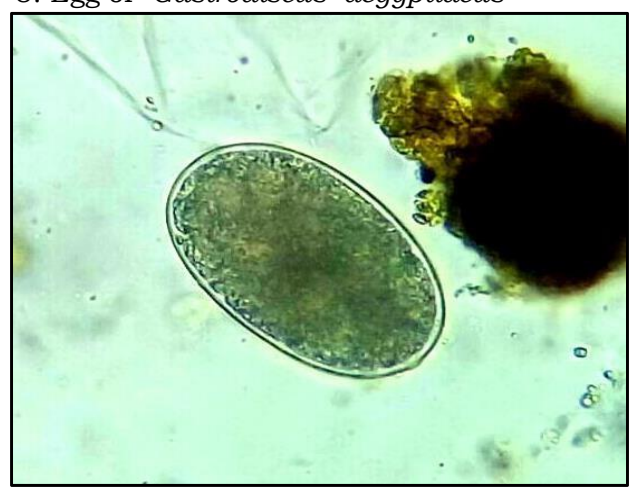

11.Egg of Ancylostoma duodenale

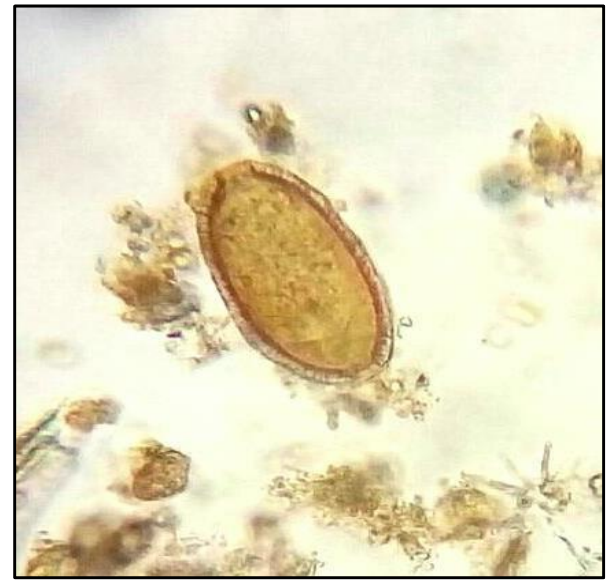

12. Egg of Capillaria $s p$. 


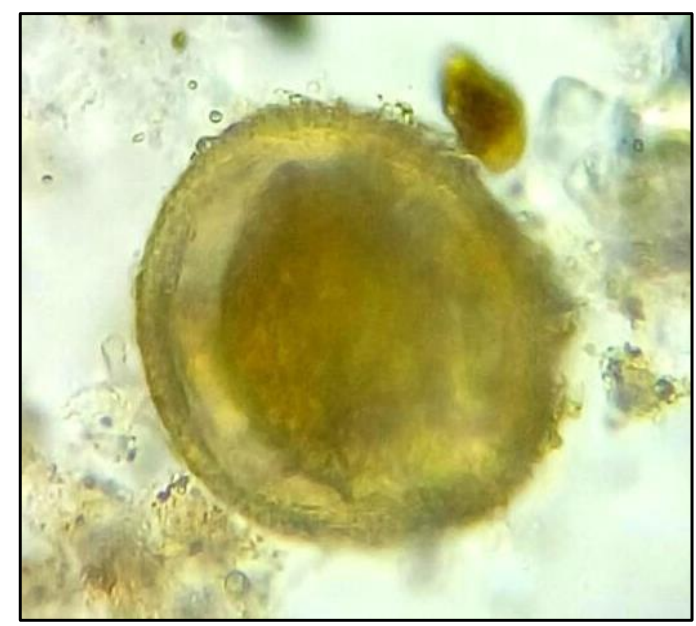

13. Egg of Toxocara sp

Hymenolepis nana. The lowest prevalence was $16.67 \%$ for Taenia sp. and Fasciola hepatica. Intensity $(37.83 \pm 29.17)$ was highest in Isospora sp. and lowest $(1 \pm 0.28)$ in Taenia sp. The prevalence of the parasite was statistically significant $(\mathrm{p}=0.003, \mathrm{p}<0.05)$.

Out of 48 samples 47 samples (97.92\%) were positive for gastrointestinal parasites infection. The observation of the present study is almost similar with Fikru et al. (2005), Sheferaw and Alemu (2015) from Ethiopia who have reported $98.2 \%$ and $100 \%$ prevalence respectively. This finding is much higher than the other studies done in different countries. Previous study showed 89.29\%, 84.0 $\%$, and $86.6 \%$ of overall prevalence by Hassan et al. (2005), Adeppa et al. (2016), Anazi and Alyousif (2011) respectively. However low prevalence was also found from previous study which was $14.43 \%$ by Sultan et al. (2014). Management and ecological condition could be the reason of this variation.

From this study 15 genera of gastrointestinal parasites were recorded. Among them 2 genera of protozoa (Isospora sp. and Entamoeba sp.), 4 genera of cestode (Hymenolepis nana, Taenia sp., Moniezia benedeni and Thysaniezia sp.), 3 genera of trematode (Fasciola hepatica, Gastrodiscus aegyptiacus and Opisthorchis sinensis) and 6 genera of nematode (Ancylostoma duodenale, Parascaris equorum, Trichuris sp., Capillaria sp., Toxocara sp. and Oxyuris equi) were found. Among different groups of parasites the highest prevalence was recorded $93.75 \%$ in case of nematode followed by $79.2 \%, 70.8 \%$ and $31.25 \%$ for cestode, protozoa and trematode respectively. This is in line with Matto et al. (2015) from Mumbai and Pune. Highest prevalence was recorded for Parascaris equorum $(77.1 \%)$. 
Prevalence of other parasite species identified were $70.8 \%$ in Hymenolepis nana, $62.5 \%$ in Isospora sp., $50 \%$ in Ancylostoma duodenale, $39.6 \%$ in Toxocara sp., $35.4 \%$ in Entamoeba sp., $25 \%$ in Trichuris sp., $20.8 \%$ in Fasciola hepatica $16.67 \%$ in Capillaria sp., $8.3 \%$ in Taenia sp. and Opisthorchis sinensis, $4.2 \%$ in Moniezia benedeni and Thysaniezia sp. and $2.1 \%$ in Gastrodiscus aegyptiacus and Oxyuris equi.

In protozoa Isospora sp. and Entamoeba sp. were recorded which is similar to the findings of Dissanayake et al. (2017) who recorded $13.7 \%$ Isospora sp. and $28.8 \%$ Entamoeba sp. This prevalence rate is much lower than current study.

In cestode group prevalence of Hymenolepis nana $62.5 \%$ was highest. This was not recorded by previous researchers. Various species of beetle and fleas serve as intermediate host. Definitive hosts are human and rodents. As rodents are common in household and domesticated area horse may be infected while feeding with contaminated faeces which contains eggs of Hymenolepis nana.

In trematode group prevalence of Fasciola hepatica (16.67\%) was highest. This rate is much higher than previous records. Epe et al. (1993) recorded 0.2\% prevalence and Epe et al. (2004) recorded 0.04\% prevalence of Fasciola hepatica in Germany. Gul et al. (2003) recorded $0.9 \%$ prevalence in Turkey, Uslu and Guclu (2007) recorded 3.6 \% Fasciola sp., Umur and Acici (2009) recorded 4.82 $\%$ Fasciola spp. in Turkey. Prevalence of Trichuris sp. was $25 \%$ which was much higher than previous finding. Uslu and Guclu (2007) recorded $0.9 \%$ prevalence of Trichuris sp. in Turkey where Mezgebu et al. (2013) recorded 1.43 $\%$ prevalence of Trichuris sp. in donkey from Ethiopia.

The least prevalence was $2.1 \%$ for G aegyptiacus and Oxyuris equiwhich is similar with Fikru et al. (2005) who reported $2.1 \%$ prevalence in $O$ equi. Least prevalence of $O$. equi was recorded by Sengupta and Yadav (1998), Anazi and Alyousif (2011), Sultan et al. (2014), Adeppa et al. (2016), Shah et al. (2016). Sengupta and Yadav (1998) reported low prevalence of $(2.8 \%)$ for O. equi in horse in Haryana, India which is almost similar with present finding. It may be due to the similarity of climatic condition. Mezgebu et al. (2013) reported 2.86 $\%$ Gastrodiscus aegyptiacus which is quite similar with present finding $(2.1 \%)$. Islam (1986) recorded $4.72 \%$ Gastrodiscus aegyptiacus, Adeppa et al. (2016) recorded $7.14 \%$ Gastrodiscus aegyptiacus in India which was higher than the present record.

However Ancylostoma duodenale, Hymenolepis nana, Taenia sp., Moniezia benedeni, Thysaniezia sp., Opisthorchis sinensis, Capillaria sp. and Toxocara sp. were encountered as new findings in present study. These parasite species are common in herbivore animals. As horse is also an herbivore animal, it may be contaminated by these parasites during feeding, lack of deworming, favourable condition for contamination and low immunity. Moniezia benedeni 
and Thysaniezia sp. use oribatid mites as their intermediate host. Horse can be infected with these parasites by ingestion of infected soil mites.

Highest intensity was found in case of Isospora sp. (72.97 \pm 46.32$)$ followed

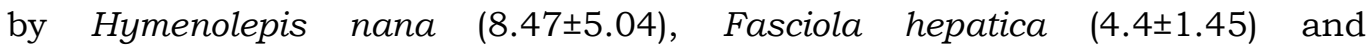
Parascarisequorum (2.92 \pm 1.31$)$. Lowest intensity was found $(1 \pm 0.04)$ in case of Gastrodiscus aegyptiacus and Oxyuris equi. The p value was $0.01, \mathrm{p}<0.05$ so the prevalence rate was statistically significant for this study.

The study demonstrated $100 \%$ prevalence in female which is higher than male prevalence $95.45 \%$. This is in agreement with Wosu and Udobi (2014). Sultan et al. (2014) reported females are highly infected than male in case of Strongylae spp. in Ethiopia. On the other hand Matto et al. (2015) reported prevalence of male equids $(20.93 \%)$ was higher than female $(19.49 \%)$. However Belay et al. (2016) and Taye (2017) reported that there was no statistically significant difference in prevalence of gastrointestinal parasites based on sex.

Season had a significant effect on prevalence of gastrointestinal parasites and it was statistically significant $\mathrm{p}<0.05$. The highest prevalence was recorded in winter and Rainy season (100\%) followed by summer $(95 \%)$. This is in agreement with Chapman (2001) who reported highest prevalence in winter season. Matto et al. (2015) reported $48.57 \%$ prevalence in monsoon followed by $38.89 \%$ in winter and $31.11 \%$ in summer. Different findings were found by Musa et al. (2016) where highest prevalence was in case of summer and late autumn in Western Sudan. The prevalence of Parascaris equorum was highest in winter season followed by rainy and summer. Similar finding was found by Anazi and Alyousif (2011) in Saudi Arabia.

Prevalence of Isospora sp., Entamoeba sp., Hymenolepis nana and Taenia sp. was aslo found highest in winter season (Chapman et al. 2001). As the pregnancy period of horse lasts upto late spring it could be the reason of highest prevalence in winter season. Opisthorchis sinensis and Oxyuris equi were only found in rainy season. Prevalence of Ancylostoma duodenale, Trichuris sp., Capillaria sp. and Toxocara sp. was highest in rainy season. In rainy season humidity and climatic condition are favourable for development of parasitic stages. However the prevalence of Fasciola hepatica was recorded highest in summer season. Intensity of parasites was highest in rainy season (63.38 $\pm 79.94)$ followed by summer $(55.47 \pm 29.73)$ and winter $(49.5 \pm 28.58)$.

Conclusion: Although horse is not considered an important livestock animal in terms of monitory benefit in Bangladesh, however parasite infestation can be a source of transmission to other livestock animals as they may share the same pasture. Captive breeding and handling of horses in captive environment should focus on cleanliness and hygiene practice of handlers because the parasites of 
horses can have zoonotic importance. Control measures like antihelminth drug therapy in zoos and other horse rearing farms should be implemented.

\section{LITERATURE CITED}

ADEPPA, J., ANANDA, K.J., KRISHNA MURTHY, C.M. and SATHEESHA, G.M. 2016. Incidence of gastro-intestinal parasites in horses of Shimoga region, Karnataka state. J.Parasite.Dis.40(3):919-921.

ALAM, M.P., BHUIYAN, M.S.A. and BHUIYAN, A.K.F.H. 2015. The socio-economic status of Horse owners in rural areas of Bangladesh. J. Agric.13(1): 46-52.

ALTAS, M.G., GOKCEN, A. and SEVGILI, M. 2007. Prevalence of helminth species in Arabian horses. Indian Vet J. 84: 1093-1094.

ANAZI, A.D. and ALYOUSIF, M.S. 2011. Prevalence of non-strongyle gastrointestinal parasites of horses in Riyadh region of Saudi Arabia. Saudi J. Biol. Sci.18: 299-303.

ANDERSEN, U.V., HOWE, D.K., OLSEN, S.N. and NIELSON, M.K. 2012. Recent advances in diagnosing pathogenic equine gastrointestinal helminth.: The challenge of prepatent detection .Vet Parasitol. 192:1-9.

BANGLADESH ECONOMIC REVIEW. 2014. Finance Division, Ministry of Finance, Government of Peoples Republic of Bangladesh.

BELAY, W., TESHOME, D. and ABIYE, A. 2016. Study on the Prevalance of Gastrointestinal Helminthes Infection in Equines in and around Kombolcha. J. Vet. Sci. Technol. 7: 5.

BIFFA, D. and WOLDEMESKEL, M. 2006. Causes and Factors Associated With Occurrence of External Injuries in Working Equines in Ethiopia. Int. J. Appl.Res. M.4: 1-7.

BLISS, D.H. 1999. The control of gastrointestinal nematode parasites in horses with emphasis on reducing environmental contamination. "A new control strategy for an old problem." Mid America Ag. Res. Verona. WI. 53593.

BUCKNELL, D.G., GASSER, R.B. and BEVERIDGE, I. 1995. The prevalence and epidemiology of gastrointestinal parasites of horses in Victoria, Australia. Int. J. Parasitol.25: 711-724.

CHAPMAN, M.R., FRENCH, D.D. and KLEI, T.R. 2001. Seasonal transmission of gastrointestinal parasites of Equids in southern Louisiana. J. Parasitol. 87(6): 1371-1378.

CHATTERJEE, K.D. 1980. Parasitology. Chatterjee Medical publishers Calcutta.

CHEESBROUGH, M. 1987. Medical Laboratory Manual for Tropical Countries. ELBS Publishing, UK.

CHENG, T.C. 1997. General Parasitology. Academic Press, USA.

CHOWDHURY, S.I. 1979. Arthitinic Bhugal (In Bengali). Puthighar Publishers, Dhaka, pp 340-353.

DISSANAYAKE, S., RAJAPAKSE, R.P.V.J and RAJAKARUNA, R.S. 2017.Gastrointestinal parasites of domesticated and Feral Horses (Equus Caballus) in Sri Lanka. Ceylon J. Sci. 46(1): 17-26. 
EPE, C., COATI, N. and SCHNIEDER, T. 2004. Results of parasitological examinations of faecal samples from horses, ruminants, pigs, dogs, cats, hedgehogs and rabbits between 1998 and 2002. Dtsch. Tierarztl. Wochenschr. 111: 243-247.

FIKRU, R., RETA, D., TESHALE, S. and BIZUNESH, M. 2005. Prevalence of equine gastrointestinal parasites in western highlands of Oromia, Ethiopia. Bulletin of Animal Health and Production in Africa 53: 161-166.

FRANCISCO, I., ARIAS, M., CORTINAS, F.J., FRANCISCO, R., MOCHALES, V.,

DACAL, V., SUAREZ, J.L., URIARTE, J., MORRONDO, P., SANCZANDRADE, R., DIEZ-BANOS, P. and PAZ-SILVA, A. 2009. Intrinsic factors influencing the infection by helminth parasites in horses under an Oceanic Climate Area (NW Spain). J. Parasitol. Res.7: 225-230.

GAWOR, J., KORNAS, S., CHARCENKO, V., NOWOSAD, B. and SKALSKA, M. 2006. Intestinal parasites and health problems in horses in different breeding systems. Medycyna Weterynaryjna. 62: 331-334.

GETACHEW, A.M., INNOCENT, G., PROUdMAN, C.J., TRAWFORD, A., FESEHA, G., REID, W.J., FAITH, B. and LOVE, S. 2012. Equine cestodosis: a seroepidemiological study of Anoplocephala perfoliata infection in Ethiopia. Vet. Res. Commun.36: 93-98.

GUL, A., DEGER, S. and AYAZ, E. 2003. The Prevalences of Helminth Species According to Faecal Examination in equids in Different Cities in Turkey. Turk. J. Vet. Anim. Sci. 27: 195-199.

HARDIN, D.K. 1997. Controlling Internal Parasites of the Horse. Agricultural MU Guide, University Extention, University of Missouri-Columbia. Inside a Modern Baseball". Baseball Fever. Baseball Almanac. Retrieved 2008-04-03.

HASSAN, R., KHAN, M.A., AKHTAR, T., KHAN, I., ABBAS, T. and YOUNUS, M. 2005. Epidemiology of parasitic load and therapeutic control against ecto and endoparasites with ivermectin in horses. Punjab Univ. J. Zool. 20(2): 143-150.

HINEY, K. and GIEDT, E. J. 1914. Common Internal Parasites of the Horse.

KHAN, A., KHAN, M.S., AVAIS, M., MAHMOOD, A.K. and IJAZ, M. 2010. Prevalence and Chemotherapy of Parascaris equorum in Equines in Pakistan. J.Equine Vet. Sci. 30: 155-158.

KHAN, M.A., ROOHI, N. and RANA, M.A.A. 2016. Strongylosis in Equines: A Review. J. Anim. Plant Sci. 25(1): 1-9.

LARSEN, M.M., LENDAL, S., CHRIEL, M., OLSEN, S.N. and BIORN, H. 2002. Risk factors for high endoparasitic burden and the efficiency of a single anthelmintic treatment of Danish horses.Acta Vet. Scand.43: 99-106.

LIND, E.O., HOGLUND, J., LJUNGSTROM, B.L., NILSSON, O. and UGGLA, A.

1999. A field survey on the distribution of strongyle infections of horses in Sweden and factors affecting faecal egg counts. Equine Vet. J.31: 68-72.

LYONS, E.T., TOLLIVER, S.C. and KUZMINA, T.A. 2012. Investigation of strongyle EPG values in horse mares relative to known age, number positive, and level of egg shedding in field studies on 26 farms in Central Kentucky (2010-2011). Parasitol. Res.110: 2237-2245. 
MATTO, T.N., BHARKAD, G.P. and BHAT, S.A. 2015. Prevalence of gastrointestinal helminth parasites of equids from organized farms of Mumbai and Pune. J. Parasit. Dis. 39(2):179-185.

MEZGEBU, T., TAFESS, K. and TAMIRU, F. 2013. Prevalence of Gastrointestinal Parasites of Horses and Donkeys in and around Gondar Town, Ethiopia. Open J. Vet. Med.3: 267-272.

MITREA, L.I. 2011. Parazitologie si Boli Parazitare. Ceres Publishing House, Bucharest.

MUSA, M.T., WAHAB, M.B.A. and ADAM, M.E. 2016. Internal and External Parasitic Infections of Equines in South Darfur State, Western Sudan. U. of K.J. Vet. Med. Anim. Prod.7(1): 1-9.

PANCHEVA, M.S.P.2013. Parasites in captive animals: A review of studies in captive European zoos. Zool Gart.82:1-2.60-71.

RAHMAN, S.M., DEY, A.R., KUNDU, U.K. and BEGUM, N. 2014. Investigation of gastrointestinal parasites of herbivores at Dhaka National Zoological Garden ofBangladesh. J.Bangladesh Agril. Univ. 12(1): 79-85.

REHBEIN, S., VISSER, M. and WINTER, R. 2013. Prevalence, intensity and seasonality of gastrointestinal parasites in abattoir horses in Germany. Parasitol. Res. 112: 407413.

SCHMIDT, G.D and ROBERTS, L.S. 1996. Foundations of Parasitology. Times Mirror Company. USA.

SENGUPTA , P.P. and YADEV, 1998. Incidence of gastrointestinal parasites in organized and unorganized equine farms in Haryana. Indian J Anim Sci. 68(12): 1228-1220.

SOULSBY, E.J.L. 1982. Helminths, Arthopods and Protozoa of Domesticated Animals. $7^{\text {th }}$ Edition. Bailliere and Tindal, London, 766-771pp.

SUltan, A., AYELE, G., TADESSE, B. and AHMED, A. 2014. Prevalence of gastrointestinal parasites of horses and donkeys in Kurfa Chale District, East Hararghe, Ethiopia. Livestock Research for Rural Development. 26(7): 1-9.

SWAN, W.J.2006. Improving of welfare of working equine animals in developing countries.Appl. $.100(1-2): 148-151$.

TAYE, A. 2017. Epidemological Study on Equine Gastrointestinal Helminth Parasites in Mekelle, North Ethiopia. Open J. Vet. Med.7: 121-130.

TAYLOR, M.A., COOP, R.L. and Wall, R.L. 2007. Veterinary Parasitology. Oxford, UK; Iowa, USA; Victoria, Australia. Blackwell Publishing.

UGUR, U.and GUCLU, F. 2007. Prevalence of endoparaistes in horses and donkeys in Turkey. Bull Vet Inst Pulawy 51:237-240.

UMAR, S and ACICI, S. 2009. A survey on helminth infections of equines in the Central Black Sea Region, Turkey. Turk. J. Vet. Anim. Sci

VAN WYK, I.C. and BOOMKER, J. 2011. Parasites of South African wildlife. XIX. The prevalence of helminths in some common antelopes, warthogs and a bushpig in the Limpopo province. South Africa. Onderstepoort. J. Vet. Res. 78: 1-11.

WATSON, J. 2007. Drug Resistance in Equine Parasites: A cautionary tale. The Horse Report. 24(4): 10-11. Centre for Equine Health, School of Veterinary Medicine, University of California, One Shields Avenue, Davis, CA; 95616-8589. 
WOSU M.I. and UDOBI S.O. 2014. Prevalence of Gastrointestinal Helminths of Horses (Equus caballus) in the Southern Guinea Savannah Zone of Northern. J. Vet. Adv. 4(4): 499-502

ZASITYTE, R. and GRIKIENCIENE, T. 2002. Some data in endoparasites of common mole in Lithnani. Acta Zool. Lit. 4: 403.

(Manuscript received on 05 August 2021 revised on 30 August, 2021) 